\title{
Lessons from an Innovation-leader and Tools to Learn Them
}

\author{
Bill Williams ${ }^{1,2}$, José Figueiredo ${ }^{2}$ \\ ${ }^{1}$ ESTBarreiro, Setubal Polytechnic Institute (Portugal) \\ ${ }^{2}$ CEG-IST, Instituto Superior Técnico, Universidade de Lisboa (Portugal) \\ bill.williams@,estbarreiro.ips.pt, jdf@,tecnico.ulisboa.pt
}

Received: March 2014

Accepted: July 2014

\section{Abstract:}

Purpose: A number of recent reports have suggested that communication and management skills are important competences for engineers today and are likely to continue so in the future. While participation in strategy management decisions is expected to be important for engineers in technology driven firms, little attention is given to strategy management tools in many undergraduate engineering courses. The paper demonstrates one approach to tackling this issue.

Design/methodology/approach: The authors initially present a critique of the use of standard strategy management tools SWOT analysis and Porter's 5 Forces for decision making about future company policy. This critique is then complemented by a case-study of a university start-up, a recognized innovation-leader, in which SWOT analysis, Porter's 5 Forces and PESTLE analysis are applied retrospectively as sense-making constructs to understand the firm's previous policy decisions.

Findings: The paper illustrates the potential of retrospective use of strategy management tools.

Research limitations/implications: An obstacle confronting researchers in studies of this type is that for reasons of confidentiality it is difficult to gain access to current objective data on the financial situation and policy decisions of a firm. Furthermore this work presents a single case study. Both limitations are addressed in the appropriate section of the article. 
Originality/value: The value of the retrospective use of strategy management tools is illustrated. The paper makes proposals regarding how such data can be employed in role-play activities in preparing engineers to develop interdisciplinary communication skills in the context of strategy management decision making

Keywords: strategy management tools, case-study, innovation, role-play

\section{Introduction}

A major survey of those who recruit engineers, carried out in 2006 and sponsored by the US accreditation agency ABET, asked 1,622 individuals in organizations who have extensive experience of hiring US engineers, to rank the competencies they consider as most important when recruiting. Of all the competencies, the one which they ranked the highest - even above technical ones like design, problem solving and use of technology - was "to communicate effectively" (Lattuca, Terenzini \& Volkwein, 2006).

Leydens (2012) has pointed out that the myth among engineers that data speak for themselves has been losing credence in the world of entrepreneurship and he gives the example of a study of wind power development in Europe from the early 1970s to the mid1980s, where several countries embarked on wind power technological development, but some were clearly more successful than others (Nielsen \& Heymann, 2012) What differences led to greater success for those in Denmark than in Germany? Among other contributing factors, the styles, types, and means of sociotechnical communication played a pivotal role in the evolution of wind power technology development in the two countries.

Communication and teamwork are also likely to be an important competences for engineers in the future according to reports published in the US and UK. The UK study "Engineering in the $21^{\text {st }}$ Century, the Industry View" forecast an increasing complexity of management tasks paralleled by growing technological complexity (Spinks, Silburn \& Birchall, 2006: page 4) and noted that "business is about communicating and doing work with other people, whether it's externally or internally within the company" (Spinks et al., 2006: page 22). In a similar vein the US report "The Engineer of 2020: Visions of Engineering in the New Century" published by the National Academy of Engineering predicted that "as always, good engineering will require good communication" and went on to suggest that "problems to be solved may require synthesis of a broader range of interdisciplinary knowledge" (National Academy of Engineering, 2004: page 55). At the same time it reminds us that up to now "engineers who have mastered the principles of business and management were rewarded with leadership roles" and predicts that "this will be no different in the future". 
In short, interdisciplinary communication skills and familiarity with management principles are likely to be important competences for the engineer of the $21^{\text {st }}$ century. The following sections describe a qualitative case-study which uses strategy management tools to retrospectively study the evolution of an innovative engineering company. This is followed by a discussion of how such an approach can be employed to help engineering students acquire interdisciplinary competences by participating in role-play activities based around real company histories.

This study contributes to what Boyer (1990: pages 18-21) in a report for the Carnegie Foundation describes as the scholarship of integration in that it bridges two distinct areas of study: the application of strategy management tools in firms and the use of case-study based role-play to develop interdisciplinary skills in engineering education. The following sections will give a brief overview of relevant prior studies in these two fields.

\section{Background to the study}

\subsection{Application of strategy management tools}

Although strategy management tools are commonly presented in university business courses and are frequently employed by decision-makers in technology-driven companies, they are less frequently found in engineering curricula. We would argue that they have a useful role to play in the training of future engineering practitioners in providing practice with the language and concepts frequently encountered in company management and also with the decision processes which research has shown to play a significant part in engineering practice (Williams \& Figueiredo, 2011).

A study on the use of strategy management tools in the UK published in 2009 (Jarzabkowski, Giulietti \& Oliveira, 2009) identified the ten tools most widely used by managers (see Table 1) and reported that they typically applied some combination of 3,4 or 5 of these tools, with SWOT analysis the most frequently employed, being the tool of choice for the majority (nearly $80 \%$ ) of those surveyed.

For our case study, the authors set out to retrospectively examine 2 critical moments in the life of an innovative SME: the start-up in 2000 and its globalization push 9 years later. For the latter we chose SWOT analysis, given its widespread application by managers considering such decisions. To examine the start-up conditions, we opted for Porter's 5 Forces (used by 38\%) and for PESTLE analysis (used by $32 \%$ ) as these are typically employed when considering such decisions. While these tools are normally employed to decide future strategy, our aim in this study was rather different in that we wished to use the tools to help engineering students to engage in strategy choices and compare their decisions with those taken by real world companies. 


\begin{tabular}{|c|l|}
\hline & \multicolumn{1}{|c|}{ Strategy management tools } \\
\hline 1 & SWOT \\
\hline 2 & Key Success Factors \\
\hline 3 & Core Competence Analysis \\
\hline 4 & Scenario Planning \\
\hline 5 & Value Chain \\
\hline 6 & Porter's 5 Forces \\
\hline 7 & Resource-based Analysis \\
\hline 8 & Industry Life Cycle \\
\hline 9 & PESTLE Analysis \\
\hline 10 & Portfolio Matrices, e.g. BCG or McKinsey \\
\hline
\end{tabular}

Table 1 . Top 10 strategy management tools according to a UK study

It needs to be said however, that in recent years doubts have been raised about the applicability of both SWOT and Porter's 5 Forces in the complex markets of today and the reservations are summarized in the next section.

\subsubsection{Critique of SWOT and Porter's 5 Forces analysis}

SWOT analysis began to be used by Harvard Business School academics in the 1960s although it is not clear who first developed the approach and since then has tended to be the tool of choice for management consultants. However, a rather different picture emerges when we look at the context from an engineering perspective as provided by research carried out by Hill and Westerbrook (1997) into the implementation of SWOT analysis in twenty UK firms involved in advanced manufacturing-technology activities. These firms were working in collaboration with management consultancy companies as part of a nationally funded initiative and the most commonly used tool was SWOT analysis. When the results were analyzed the researchers concluded that the so-called analyses were lacking in rigor, produced long lists, with little evidence of reflection or prioritizing or verification of the points listed. Even more worrying was the fact that, of the 37 SWOT analyses produced during this initiative, in no case were the results used in later stages of the companies' strategic processes. Hill and Westerbrook (1997) identified inadequacies both in the implementation of the instrument and with the instrument itself.

Furthermore, SWOT is usually premised on top-down strategy decisions but recent analyses of the success of innovative firms like Google have suggested that an important part of its success comes from letting small teams generate policy mediated through peer monitoring and evolutionary advantage, knowing that only $20 \%$ of the ensuing products will be successful "the company's corporate strategy is to have no corporate strategy" (Harford, 2011: page 237). Similarly Gary Hamel's study of W L Gore claims that the fact that the company structure 
is a flat lattice rather than a ladder-like hierarchy provides an internal "marketplace of ideas" which has generated more than 1000 products in its portfolio but no core business. (Hamel \& Breen, 2007)

Indeed Harford (2011: page 237) suggests that the innovative firms of tomorrow may use the power of combinatorial experiments to go one further than the Google and Gore small-team trial and error approach to strategy. He envisages them using a complexity theory methodology where they leverage technology and the power of crowds to get customers themselves to generate strategy. This could be achieved by providing them with a variety of possible products and use trial and error to identify the most successful. "When a problem reaches a certain level of complexity, formal theory won't get you nearly as far as an incredibly rapid, systematic process of trial and error".

Similarly, author Haberberg (2000) argued that SWOT may have been useful to determine strategy when it was first popularized ("when the Beatles were high in the charts and skills in marketing were relatively rare") but that in today's markets it may not be appropriate for many firms. He quotes the example of Amazon.com who might not have been expected to survive if analysed using SWOT back in the nineties but by 2000 was beginning to show the signs of the success which has become patent since then.

Despite these limitations, Haberberg (2000) concluded "SWOT analysis is fine for the initial classification of issues when we are getting to know a company, a situation or a case study" In the case of engineering education, the authors see a role for its use as a retrospectively applied instrument to understand decision-making processes in technology-led companies as in the case presented here where it can serve as an aid to lateral-thinking.

In the case of Porter's model, voices began to be heard questioning its relevance after Monitor, Michael Porter's high profile consultancy firm went bankrupt in 2012. In a stinging article in Forbes Denning (2012) questioned "why didn't the highly paid consultants of Monitor use Porter's famous five-force analysis to save themselves?" and concluded that the firm "was crushed by the single dominant force in today's marketplace: the customer".

Although the authors have not encountered major criticisms of the use of PESTLE and other strategy management tools, a case can certainly be made for applying the same reservations about their efficacy in today's rapidly changing marketplace as those been outlined above for SWOT and Porter's Forces. Indeed in an analysis of firms which have been outstandingly successful in the new economy Gary Hamel argues that "it's not the tools that distinguish industry revolutionaries from humdrum incumbents (...), instead it is their ability to escape the stranglehold of the familiar. The essence of strategy is variety" (Hamel, 2000: page 125). 
However, irrespective of the misgivings we have mentioned regarding the use of these tools for deciding future policy, we will argue in later sections that they can prove useful when applied retrospectively to follow the evolution and decision making processes of innovative firms.

\subsection{Case-study based role play in engineering education}

A paper by Trevelyan (2010), whose team at the University of Western Australia has amassed considerable empirical data about engineering practice, argues for "relocating engineering studies from the curricular margins to the core of engineering education and research". This perspective is reinforced by studies of new-engineer adjustment in companies that suggest that few novice engineers have the experience or knowledge to locate their technical competence and professional ideology within the organizational context (Baugh \& Roberts, 1994) and others which show that in companies which systematically employ organizational socialization tactics that these strongly influence newcomer integration and task mastery which in turn lead to increased satisfaction and organizational commitment (Kowtha, 2008).

All of these would seem to make a strong case for including a greater emphasis on sociotechnical professional skills as part of undergraduate training. Various institutions have attempted to design or redesign engineering and technology courses to address such issues by adopting pedagogical approaches such as service learning Coyle (Coyle, Jamieson \& Oakes, 2006), problem-based learning (Du, de Graaff \& Kolmos, 2009), case-studies (Abraham \& Abulencia, 2011), decision-making games and role-play (Burton, 1989), or virtual simulations (Nakamura, Taguchi, Hirose, Masahiro \& Takashima, 2011) to help students to develop attributes and thinking styles more appropriate for industrial practice (Savin-Baden, 2007). As yet, however, no widely-used methodology has emerged to assess the effectiveness of such initiatives, an aspect to which we shall return in section 5 .

With the increased inclusion of entrepreneurship in engineering and engineering management courses, case-studies have come to be seen as a useful pedagogical approach and journal articles focusing on real-life case-studies have become more common (see for example the International Journal of Entrepreneurship and Innovation).

\section{Objectives and Methodology of the Study}

Many students graduating from engineering schools soon encounter a very different world when they start working in a professional engineering environment and recent studies have clarified some of the differences e.g. (Anderson, Courter, McGlamery, Nathans-Kelly \& Nicometo, 2010; Domal, 2010; Faulkner, 2007; Korte, Sheppard \& Jordan, 2008; Trevelyan \& Tilli, 2007; Vinck, 2003). Although strategy management tools are commonly presented in 
university business courses and are frequently employed by decision-makers in technologydriven companies, they are less frequently found in engineering curricula. Thus, the authors contend they have a valuable role to play in the training of future engineering practitioners in providing practice with the language and concepts frequently encountered in company management and also with the decision processes which research has shown to play a significant part in engineering practice (Williams \& Figueiredo, 2011).

Given that the vast majority of teaching and learning in most higher education engineering courses tends to be devoted to technical analysis and skills, with some attention to problem-solving aspects of future professional life, we have suggested in a previous study (Williams \& Figueiredo, 2013) that there is a need for engineering education to develop a broader set of professional skills which includes interaction and communication competences and for a range of management skills to be developed within the repertoire of tomorrow's engineers. We propose that case studies of relevant technology-driven firms can make a valuable contribution to such a curriculum, that strategy management tools can provide a valuable structure for this and we illustrate this by providing an example of the implementation of role-play based on our case-study.

The value of the approach is exemplified in this paper by a case study, which employs three commonly applied strategy management tools to stages of the development of a company recognized as an innovation leader. The objectives of this case-study are two-fold:

- to demonstrate how strategy management tools can be employed to understand decision-making processes in an innovative technology-led company

- to propose an application of this analysis in the context of a role-play exercise for training of engineers in $3^{\text {rd }}$ level or subsequent courses.

In her paper Building Theories from Case Study Research, Eisenhardt (1989) suggests that small-scale case studies can be particularly valuable for theory building in the early stages of research on a topic or when the research is in an area where existing theory seems inadequate. Accordingly it was decided to initially choose a firm that was a recognised innovation leader and use a qualitative approach based around the use of strategy management tools as framing constructs.

\subsection{The company selected for the case study}

When Gary Hamel's consultancy firm Strategos (2009) polled 186 CEOs and senior figures in leading Portuguese companies to gather data on which international and national firms they considered to be the most innovative, the results were awaited with interest. The Portuguese company with the highest vote was YDreams, a start-up created in 2000 when a group of 
engineers from a successful university research department at a Lisbon university (Universidade Nova de Lisboa) felt the need to move from a university to an entrepreneurial context. YDreams has since had considerable national and international success in the areas of interactive spaces.

The key engineers in this start-up were originally in the field of Environmental Engineering and Information Technology, and their Environmental Systems Analysis Group (GASA) was known for its pioneering work in a field that has since become dominated by Google Maps. In 2000, frustrated by the limitations encountered within the academic system, they effectively set aside the projects they had been working on and dedicated themselves to an entrepreneurial start-up. Their YDreams company has since come to enjoy considerable international success in the interactive space and ubiquitous computing sectors (http://www.ydreams.com/). With an initial investment of 50 thousand euros in 2000, by 2010 the firm reportedly had an annual turnover of over 9 million euros and its clients have included Vodafone, NOKIA, JC Decaux Airport, Siemens, Alcatel, Endemol and the BBC. CEO Antonio Câmara won the prestigious Pessoa Prize in 2006 (COTEC, 2005) for his entrepreneurial achievements and the company has won a number of international awards including the Industrial Design Society of America Gold Award for Interactive Environments in 2004, and an Auggie (Augmented Reality Award) in 2010.

\subsection{Analytical instruments employed in the case study}

As we believe the study of the strategy of innovative companies can provide important learning contexts for engineering students, we propose that instructors can model how this can be done using strategy management tools so that students can then go on to develop case studies, using SWOT for example, which can contribute to capstone projects. A practical difficulty which arises with this approach is that instructors and students may not gain access to senior decision makers or be able to acquire data of a financial nature of a company they wish to study. For this reason, in the study reported here we applied the SWOT analysis of the globalization strategy to publicly available information about the firm under study to see to what extent this allowed us to put together a characterization of the decision-making process of the start-up being studied. Moreover, in this case we were able to validate this data via a subsequent interview with the YDreams CEO in 2011.

Thus, this work is based on both secondary data from published interviews, public presentations by staff of the company and on primary data obtained in semi-structured interviews with the CEO and CFO about the company's start-up carried out in 2009. The further interview with the CEO carried out in 2011 to validate the data obtained from public sources provided valuable insights into strategy refashioning in a time of economic crisis. 
Although the main focus of the original 2009 interviews was the practice of the group of engineers who had participated in the transition from being a successful university research centre to becoming a leading innovative company, the narrative approach employed also led to reflection by the interviewees on organizational strategy over the nine-year period since the start-up in 2000. Given the current interest in technology-led start-ups and academic spinoffs, one focus of this work will be an analysis of the context in 2000 when this group of academic engineers set out to make the transition to the entrepreneurial sphere. To this end, Porter's Five Forces model and PESTLE analysis are used to study the context within which the group was operating when they prepared to launch the company in 2000 . This is complemented with data describing the first nine years of the company.

The second focus of this work deals with strategy considerations for the internationalization of YDreams in 2010 - ten years on from the initial change from university research group to fully-fledged company. This has been an objective of the company from the start but given the current economic conjuncture in Portugal there has been a strong impulse among national firms to reinforce their efforts in gaining revenue from international markets to help cope with the downturn in the national one. The national business press has been giving extensive coverage to these developments on the part of leading Portuguese companies and there have been a number of published interviews with YDreams CEO, Antonio Câmara. Here, we employ secondary data obtained from interviews in the national press. Thus, taking an outsider perspective, we use SWOT analysis to examine the strategy options open to the company at this juncture and then use the publicly available data to see in practical terms how the company is developing its strategy to meet the challenges of internationalization.

We will now look at the founding of YDreams in 2000 through the application of PESTLE analysis and Porter's Five Forces Model.

\section{Case study}

\subsection{Analysis of the External Environment in 2000 - PESTLE}

The PESTLE model describes the Political, Economic, Sociocultural, Technological, Legal and Environmental context of the external environment within which a company aims to operate. PESTLE is mainly used to identify and to summarize environmental influences on an organization to help it to assess actual and future strategic contexts. In this case we are considering the national online and interactive space technology sector in Portugal in 2000. 


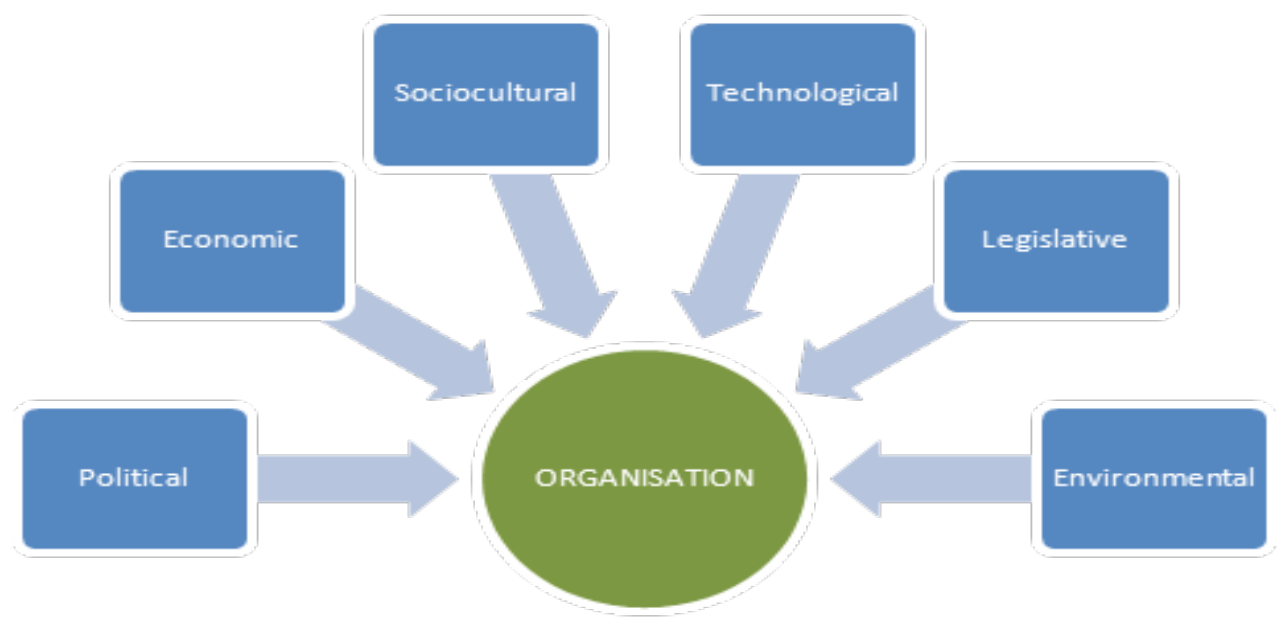

Figure 1. PESTLE analysis of the external environment of an organisation

\section{Political}

The GASA research group had felt constrained by the restrictions arising from national legislation and the rather traditional structure and practice of national higher education institutions.

\section{Economic}

Local authorities were identified as a potential market along with the emerging telecommunication mobile phone operators - indeed mobile phone operators in those heady early days were willing to fund R\&D by innovative companies.

On the other hand, it was difficult for a university research group to compete for these lines of funding and at the same time the traditional university research funding model (annual or biennial research calls) was slow and inflexible. In addition being subject to a public accounting system severely hampered the agility of the group.

One possible alternative strategy would have been to opt for a research group with a parallel incubator as had been initiated in the early 90's at the University of Coimbra with the Pedro Nunes Institute and which recently won the 2010 Best Science Based Incubator award of the Technopolicy Network ahead of 49 incubators from 23 countries (Exame Informática, 2010). 


\section{Sociocultural}

At this time computer games were well established for young people and a rapid uptake of cell-phones was underway, especially in the younger demographic groups.

\section{Technological}

Graphical screens were starting to make an appearance on cell-phones. The group had considerable knowledge capital in the area of geo-reference and mapping which would allow them to leverage their existing capabilities while at the same time entry barriers were low, allowing new entrants opportunities to gain a toehold in the market. Furthermore, although GPS was not available on the cell-phones of the time, WAP had started to be introduced and this opened up the possibility of location-based games (Nobre, 2009)

\section{Legal}

Although Portugal in common with other Southern European countries had a reputation for cumbersome bureaucracy, by the late $90^{\prime} \mathrm{s}$ the government of the time had begun to tackle the problem with the introduction of Citizen Shops and legal measures to reduce the time to set up a new company (Sousa, 1999).

\section{Environmental}

As they were initially aiming to operate in the digital domain, environmental issues were not a major constraint at this stage. 


\subsection{Analysis of the Internal Organizational Environment in $\mathbf{2 0 0 0}$ - Porter's 5 Forces Model}

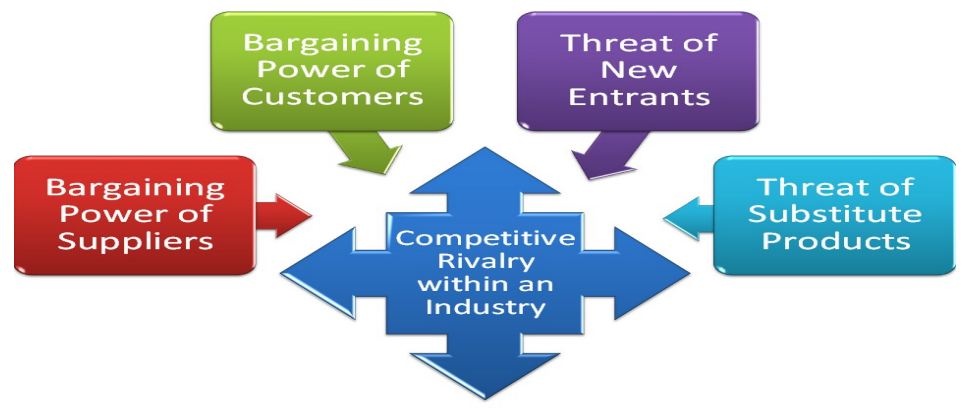

Figure 2. Porter's 5 Forces model (Porter, 2008)

\section{Intensity of competitive rivalry}

Due to early entrant status the company initially had an advantage here. However this quickly changed as new players entered the growing field and with rapid advances in mobile phone technology it would become progressively more important to diversify or integrate vertically to other fields (for example interactive physical spaces). YLabs has had a 3-fold research mission to allow the company to keep ahead of competitors (see Strategy 2000 - 2010 section below).

\section{Threat of the entry of new competitors}

This was always going to be a challenge in this sector. Although a small innovative company like YDreams may possess the agility and know-how to be a successful early entrant, "we were always being faced with the power of big players in the games and telecommunications fields once we had shown that a particular area was promising" (Nobre, 2009).

Threat of substitute products or services

As GPS became technically possible on mobile phones the early location-based WAP applications would rapidly become obsolete.

\section{Bargaining power of customers}

Right at the beginning telecommunication operators were engaged in intense rivalry for the rapidly expanding customer base in this market and Telecel (later Vodafone) was so keen to 
acquire a technological advantage it was willing to fund R\&D at the fledgling company (Nobre, 2009).

\section{Bargaining power of suppliers}

As the company was initially operating in the digital and intellectual property domains this was not an issue (although more recent work on interactive public spaces and interactive materials - smart clothes for example - could mean that this would assume a greater dimension).

\subsection{Summary of the context in 2000}

We can conclude from the above that, considering the external and internal environment at the time, the transformation from academic research group to academic start-up represented an attractive but risky strategy.

\subsection{Strategy $2000-2010$}

An initial investment of 50 thousand euros was sufficient for the start-up in 2000.

\section{Research Strategy}

YDreams CFO, Edmundo Nobre (EN): "We have our R\&D section, YLabs, which has a variety of functions and these include:

- assisting in developing the technological infrastructure for the company itself

- short-term research focused mainly on product development for our clients

- long-term research which is looking to identify future paradigm shifts so that we can be right there when things are happening (Nobre, 2009).

\section{Horizontal Diversification}

EN: "In this respect, I would give the example of our work on interactive spaces which up to now has been entirely in the digital domain but as this sector has become successively more the province of large international competitors, we have to be agile and so we have been working on the application of recent innovations in materials sciences and bubble-jet 
technology to apply our know-how to the development of novel interactive spaces in the physical domain (Nobre, 2009).

\subsection{Overall Strategy Management from 2000 to 2010}

\section{Mission}

Vice president Eduardo Dias (2007) has described the company as "Implementing mobility as a style of life" and this was reinforced by Edmundo Nobre when he spoke of aspiring to be a "cutting-edge company" which could capable of making a "national and international impact (...) rather like Nokia has done in Finland" (Nobre, 2009).

Vision

Although the company literature characterizes the overall vision somewhat generically: "YDreams is a global specialist in interaction Technologies, with a focus on Augmented Reality", a company presentation put forward the following ambitious vision (Dias, 2007):

The essence:

"A surprise maker"

The goal:

"World leader"

The technology:

"Reality computing"

The process:

"The Playbook".

This view was echoed in a press interview, where the CEO states that the overall company vision is to be a "creator of disruptive technology" (Jornal i, 2010). 


\section{Culture}

In an interview with the authors, the company culture was described by the CEO as aiming to be a "put a man on the moon" rather than be a "ride the wave" type of company (Câmara, 2008).

The Caparica headquarters in 2009 featured clusters of staff working independently in large open-plan rooms, a recreation room with ping-pong table, room for rock-band practice and a storage room containing staff mountain bikes and surfboards - features not usual in the Portuguese corporate context and which clearly signalled a corporate spirit oriented towards creativity and nonconformity.

\subsection{Internationalization 2000 - 2010}

YDreams has operated predominantly from its Caparica headquarters near Lisbon, employing around 120 staff but did open sub-offices in Brazil, Asia, Spain and at the end of 2008 had entered into a joint venture with a US firm to develop interactive products for audience entertainment (Jornal i, 2010).

\subsection{SWOT Analysis for Internationalization in $\mathbf{2 0 1 0}$}

Given that this analysis is often presented in the form of bullet points, we have opted to use this approach here to introduce the internationalization options available to the company.

\section{Strengths}

- Agility, provided by a carefully recruited staff with a strong technical background and an average age of 32 in a markedly informal and agreeable working environment;

- Structural capital (knowledge that stays with the firm) accumulated since the years of research in the GASA group allied to 10 years of successful entrepreneurial activity (patrimony like the organizational model, processes, culture and patents);

- Human capital (knowledge that stays with employees) boosted by high education standards in the field (experience, competences, abilities and skills);

- Relational, or Network, capital (knowledge that emerged from networks) linkages to external entities, scientific and technological partners, customers, and suppliers;

- Y-Lab 3-teir R\&D policy 
- The majority of staff have engineering backgrounds but with a culture of transdisciplinary teamwork which had been valuable in terms of rapid response to market changes;

- Has a good record in recruiting technologically innovative staff;

- Portfolio - over 500 projects to date for clients which have included Vodafone, NOKIA, JC Decaux Airport, Siemens, Node, IDEO, Endemol, Filmlight, Navteq (Câmara, 2008);

- Track record of producing predominantly digital technological solutions that can be licensed to partners who will assume production of the final product.

- Had also shown potential in the newly burgeoning interactive surfaces area.

Weaknesses

- Internationalization - despite the strong base in Portugal, difficulties were experienced in running and maintaining communication with branches in other countries. Although it set up local operations in Asia (2002), Spain (2004), Brazil (2005) and USA (2006), none of these appeared to be as successful as the Portugal-based parent company;

- Dimension -it was always going to be difficult for a small Portugal-based firm to compete with big-players in the US or SE Asia;

- The rapidly changing technological context can throw-up substitute products which pose a bigger challenge to small low capital companies than larger competitors;

- Lack of international business experience and knowledge - staff were largely from an engineering background and although this appears to have served the firm well at national level there could well be questions about scaling up the existing management structure to compete in a larger international context;

- Products not yet ready-for-market.

\section{Opportunities}

- Providing well-differentiated augmented reality products in a sector which has a high return on invested capital (ROIC between 20 and 30\% (Jiang \& Koller2006); 
- The US joint venture, Audience Entertainment, operating in the field of auditorium audience entertainment that had been running for about 2 years by 2010 could provide leverage to expand in the US market;

- YDreams has reached a stage where the company was capable of launching innovative products in two new distinct markets: augmented reality and interactive surfaces and the opportunities in the two markets are outlined separately as follows:

a) Augmented Reality market

- Had a proven track record in licensing innovative technological solutions to larger partners;

- Claimed to be able to provide augmented reality products which would eliminate the need for avatars as employed by principle competition in the field - "the user is the avatar";

- The augmented reality market was claimed to be worth 2,400 - 4,000 million Euros and was predicted to rise to around 40,000 million Euros over the next five years (Jornal de Negocios, 2010a);

- 4 years of preparatory investment had gone into the augmented reality internationalization project (Jornal de Negocios, 2010a);

- The augmented reality technology was mooted to be applicable outside the gaming world in contexts like general retail and e-commerce.

b) Interactive surfaces market

- The interactive surfaces market share was expected to grow to allow a turnover of 80,000 million euros in 5 years and permit break-even within 2 years (Jornal de Negocios, 2010a);

Threats

- Operating in sectors with relatively low entry threshold means rapid changing contexts;

- Vulnerability to larger more powerful competitors with better access to distribution channels;

- The current economic conjuncture in Portugal and internationally was challenging to SME activity; 
- Scaling up challenges are likely to apply in any major internationalization strategy and these would be increased significantly if the company took on two major strategic directions simultaneously.

- Fragile position in terms of financial resources.

\subsection{Internationalization Options in $\mathbf{2 0 1 0}$}

Based on the above analysis of secondary data carried out in mid-2010, we can identify sets of options associated with the two new potential markets, augmented reality and interactive surfaces. The firm could conceivably select just one or could be more ambitious and choose two options - one for each technology market.

1. Augmented Reality market

- Open a branch in a key overseas market (e.g. US);

- Form a strategic alliance with overseas company (US, Asia for example) in the augmented reality field;

- License augmented reality technology to one of the majors.

2. Interactive Surfaces market

- Open a branch in a key overseas market (e.g. US);

- Concentrate on continuing R\&D within the Lisbon parent company;

- Create a spin-out near a key foreign university or other materials research centre;

- Create a spin-out in a Portuguese region with EU support funds and low overheads.

- Moreover, assuming that the audience entertainment joint venture mentioned earlier represented a market which was already established, one could conclude that this venture would essentially call for a process of consolidation and expansion. 


\subsection{Strategy decisions taken}

The company revealed in late 2010 that it had opted to create two spin-out companies:

1. Augmented Reality market (Jornal de Negocios, 2010b)

A spin-out was announced which would function in partnership with Canesta, a Silicon Valley firm with a strong background in this field (Reuters, 2010). The product under development was claimed to be able to compete with Microsoft Kinect technology through its innovative use of interactive space. The management staff was to be based in San José whereas R\&D would continue in Caparica, Portugal. The firm aimed to achieve a turnover of 150 million euros in 5 years.

2. Interactive Surfaces market (Jornal de Negocios, 2010a)

Plans for growth in this market were realized by the creation of Ynvisible, a spinoff based in Cartaxo, Portugal (a priority region where public funds were available to encourage new enterprises). This was to be launched on the Frankfurt Stock Exchange early in 2011. It was set to have an initial staff of ten including engineers and managers with products expected to appear in 2011.

The new firm was expected to leverage existing collaboration within a network of many of the leading Portuguese companies in manufacturing sectors like cement, paper and cork: Amorim, Portucel, Secil, Sonae etc. In addition to existing national investors BES and Herrick Partners, it also gained new investment from CUF, Portugal and support from Rennelbank in Germany. The stated aim of the new firm was to achieve a turnover of 70 million euros in 5 years and break-even was predicted in 2013 (Jornal de Negocios, 2010a).

\section{2011: Validation of the secondary data used for the SWOT Analysis}

As the years 2010 and 2011 represented a period characterized by significant economic shocks and Portugal was one of the EU countries particularly affected, we revisited the company's strategic plans one year later to examine how it had been responding strategically to the economic turbulence. In this case we obtained primary data in the form of an interview with the CEO, António Câmara and found that in a short period of time the firm had needed to display considerable agility and undergo profound changes to its strategic thinking in a bid to maintain growth. 
The CEO revealed that the economic situation had forced the firm to make two major strategic changes in a short period of time in that they were obliged to rethink both the market priorities and the structure of the company itself.

\subsection{Market strategy}

Adapting to changes in the economic context necessitated drastic change in the firm's strategy and rapid change in locations to find new markets in parts of the world where the economic climate is more propitious:

"In keeping with the rest of Portugal, we found ourselves facing a massive crisis and our domestic market effectively dried up which forced us to be almost completely orientated towards the exterior. The national market today represents around 3\% of our turnover whereas not too long ago it was $70 \%$. Although we have managed to increase our presence in various world markets (in the US in particular but also Turkey and Russia) the main shift has been towards Brazil that in a brief space of time has become our principal market. Many of our staff from the headquarters have now moved to Brazil so that apart from our R\&D group which remains here, the heart of YDreams is now located in Brazil where we have our new headquarters in Rio and the production and commercial departments are in São Paulo".

\subsection{Company structure}

At the same time, the company made rapid and significant changes to its organizational culture and structure:

"Simultaneously with the change in market strategy, we also decided to change our organizational culture and see ourselves as having a multicellular structure similar to the Netflix model. In other words, in an attempt to preserve the start-up spirit, which has always been a strong point of ours, we are now effectively 5 companies: in addition to YDreams itself which continues to carry out project design, sales and R\&D thee are four recent spinouts: Ynvisible the interactive surfaces company recently launched on the Frankfurt stock exchange, YVision specializing in augmented reality as a missing link between Game Engines and Natural User Interfaces, YRobotics concentrating on robotics and mechatronics and finally Audience Entertainment a joint-venture with a North American partner that is based in New York and focuses on audience interactivity in cinemas and other large venues based on a sponsored entertainment platform. This last has brought us a lot of visibility as we currently have our audience interaction action game running before the main feature in major cinemas in the twenty largest cities in the US and upcoming in Cannes, London, Athens and Shanghai". 
"These four spinouts all have new CEOs and their management teams have a common priority of hiring top class business development specialists as we have come to see this as a key success factor".

We note that the strategy involving a partnership with a Silicon Valley company a setting up a branch there had been abandoned and Union Square, New York had been chosen for its US centre of operations, on the back of the Audience Entertainment success.

In addition to the strategic management choices described above, one can observe a further element of YDreams strategy which would not have been part of the repertoire of firms 20 or 30 years ago, when many of today's strategy management tools first appeared, but which now represent an important item in the armoury of digital technology-driven companies: cyber buzz. YVision has been using the power of crowd-sourcing by making a beta of an augmented reality program freely available to the public at large and partly as a consequence YDreams and its spinouts have been name-checked in Wired magazine and in the blogs of Wired writers and a YRobotics product received a one-page feature in the August 2011 edition of its UK edition (Wired UK, 2011).

\section{Case-study based role play}

Although better known for his contributions to management, Henry Mintzberg, trained as a mechanical engineer and he has pointed out that no one gets to practice surgery without prior training in the classroom (Mintzberg, 2009: page 228). There is an essential difference, however, in that surgeons go through a two stage learning process which includes both theoretical training and hands-on clinical practice whereas that of engineers in most parts of the world is based around a one-stage engineering-science based education (Heywood, 2014). However various authors (Trevelyan, 2010, 2013; Williams \& Figueiredo, 2011; Williams \& Figueiredo, 2013) have argued that you cannot understand what engineers do until you consider what engineering is: "a social performance in which expertise is distributed among the participants and emerges from their social interactions" (Trevelyan, 2010). Thus it becomes important to develop approaches to prepare future engineers or recently graduated novice engineers by using approaches which allow them to build a repertoire of performancebased competences to successfully engage with other actors in socio-technical contexts.

To contribute to the repertoire of such approaches we would propose the use of the kind of case study and narrative approach outlined in this paper, one which plays to the strengths of strategy management tools as part of a descriptive and analytical framework and which can provide material and a framework for role-play activities suitable for inclusion in this kind of broader approach to engineering education. Our experience with the use of role-play with engineering undergraduates would reinforce Nakamura's comment that "a lack of 
understanding of the stakeholders' roles assigned to learners has meant that students have not really been able to fully appreciate the project management scenario that they have been role-playing" (Nakamura, Takashima and Mikami, 2010). For this reason we have found it important to build these activities around real cases which are seen to be relevant to students rather than creating hypothetical situations or using virtual simulations.

Following Felder and Brent (2003), we consider a jigsaw activity approach to be appropriate here - one where groups of participants are supplied with different information and need to come to a consensus in a role-play. One possible application would be to use a 2-stage approach. First focusing on YDreams strategy in 2000 and distributing the information contained in the Porter 5 Forces analysis to one group of students while other receive the PESTLE analysis. The different groups then prepare and role-play a board meeting where they come together to plan company strategy over the next 10 years. After instructor-facilitated feedback between the groups, the students learn what the real company options were during that period.

The second stage would again involve 2 groups in a jigsaw activity role-playing a board meeting and in this case participants are supplied with different parts of the SWOT analysis data for the company's globalization in 2010, and similarly come to agreement on strategy options. Once again this is followed by discussion on the real company choices and their outcomes.

\section{Evaluation of learning outcomes}

We are still at an early stage in terms of evaluating the use of role-play and case study approach in our own institutions but as the learning outcomes to be achieved with this approach involve changes in individual students such as their perceptions of the engineer's role in the strategy management of a firm or of engineering workplace activity, phenomenography would be the method of choice. This is a qualitative methodology which focuses on the ways in which learners differ (Marton, 1989) with regard to specific phenomena and a useful introduction to its use in engineering education can be found in a paper by Mann, Dall'Alba, and Radcliffe (2007).

This method has been used in engineering education to evaluate size and scale in nanoscale science and technology contexts (Swarat, Light, Park \& Drane, 2010), and transient responses in student problem solving contexts (Carstensen \& Bernhard, 2009). It is also beginning to emerge in other engineering contexts as well. For example, it has been used to identify conceptions of competent work among engineers in an auto manufacturing company (Sandberg, 2000) and conceptions of the value of information-technology (IT) research among IT researchers and practitioners (Bruce, Pham \& Stoodley, 2004). 


\section{Limitations of the case-study}

An obstacle confronting researchers in studies of this type is that for reasons of confidentiality it is difficult to gain access to current objective data on the financial situation and policy decisions of a firm (Ahmad \& Seymour, 2008). The authors tackled this by culling data on the situation of YDreams in 2010 from press interviews published at that time. Although the objectivity of such secondary sources may be compromised, the authors then triangulated with primary interview data a year later by asking the CEO to confirm the 2010 data and to relate how things had changed in the intervening year and we believe that this procedure allowed us to be able to publish data which has an acceptable degree of objectivity for a case-study in such an entrepreneurial context. For this reason, a small number of the references cited are from newspaper articles rather than academic publications.

Another limitation arises from the fact that only one company was studied and only two senior staff members contributed and this does limit the degree of generalizability. Nevertheless, in exploring a single case the authors align with a growing trend in academy that recognizes that the single case may promote reflection and generate useful theory (Flyvbjerg, 2006; Eisenhardt \& Graebner, 2007). It was mentioned in section 3 that Kathleen Eisenhardt (1989) suggests that small-scale case studies can be particularly valuable for theory building in the early stages of research on a topic. She also claims out that testing existing theory on case studies may provide serendipitous findings which can lead to new insights. This particular case study did in fact lead to valuable insights which enabled the authors to identify fruitful lines of inquiry for a successful large-scale study into interaction in the engineering workplace where we gathered empirical data on the activities of engineers in companies and the time they devoted to these activities. This was achieved by collecting quantitative information via an online survey of 247 engineers and qualitative information through semi-structured interviews with 23 practicing engineers in a range of contexts ranging from SMEs to large national and international marketleaders. This in turn has allowed us to propose a visual representation of the engineer in the workplace using an actor-network approach which we published in a recent book (Williams \& Figueiredo, 2013).

With regard to future lines of research, realizing that role playing and strategic tools by themselves may not necessarily contain sufficient detail to allow students to understand the decision making process conducted by the firms or to understand the full context of the case study, we propose to integrate a boundary object (BO) approach in future work. BOs are artifacts (designs, tools, classifications, sketches, codes, standardized methods) shared by heterogeneous actors which serve as a point of mediation and negotiation around project intent (Star \& Griesemer, 1989, Carlile 2002, Trompette \& Vinck 2009). This approach has been used in a variety of empirical contexts involving multidisciplinary teams: Star and Griesemer (1989) introduced the notion in a study of scientific work in a natural history museum, Carlile (2002) applied it to new product development in an automotive firms, Vinck 
(2003: pages 172, 191) studied work in a design offices while Mazur and Chen (2010) have employed it in the evaluation of industrial engineering students' competencies. Following on from our own empirical study of engineers in Portugal and our characterization of the engineering workplace as a network of heterogeneous actors (Williams \& Figueiredo, 2013) the BO concept would appear to be an appropriate construct to frame future research in this area.

\section{Conclusions}

As stated in section 2, the case-study presented makes a contribution to two distinct fields of study. In a contribution to theory, it first presents a critique of frequently used strategy management tools, SWOT, Porter's 5 Forces and PESTLE in defining strategy of firms in the new economy. Then the authors demonstrate how these tools may be employed retrospectively using primary and secondary data to characterize the evolution of an innovative firm and the decision processes involved at both the start-up stage and 10 years later when it was embarking upon a major globalization push. The primary data gathered for validation of the secondary data used in the SWOT analysis also provides a vivid illustration of how technological start-ups are required to change rapidly to react in a time of economic downturn. In a supplementary contribution to theory the case presented illustrates Eisenhardt's claim (1989) that exploratory case-study research can open the way to broader research lines which can lead to new insights (Williams \& Figueiredo, 2013).

In addition the paper proposes an application for this approach in the training of engineers by using role-play activities based on a successful innovative firm, it suggests how learning outcomes could be evaluated using a phenomenographic methodology and it points towards the potential of the boundary object concept to frame future research.

\section{Acknowledgement}

This work is supported by a grant from the Fundação para a Ciência e a Tecnologia (FCT) of the Portuguese Ministry for Education and Science as part of the project What Engineers Do PTDC/CPE-PEC/112042/2009.

\section{References}

Abraham, N.S., \& Abulencia, J.P. (2011). Use of the LITEE Lorn Manufacturing Case Study in a Senior Chemical Engineering Unit Operations Laboratory. Journal of STEM Education: Innovations and Research, 12(3), 9-16. 
Ahmad, N., \& Seymour, R. (2008). Defining Entrepreneurial Activity: Definitions Supporting Frameworks for Data Collection. OECD Statistics Working Papers 2008/1. OECD Publishing.

Anderson, K.J.B., Courter, S.S., McGlamery, T., Nathans-Kelly, T.M., \& Nicometo, C.G. (2010). Understanding engineering work and identity: a cross-case analysis of engineers within six firms. Engineering Studies, 2(3), 153-174. http://dx.doi.org/10.1080/19378629.2010.519772

Baugh, S.G., \& Roberts, R.M. (1994). Professional and organizational commitment among engineers: conflicting or complementing? IEEE Trans. Eng. Manage., 41(2) 108-114. http://dx.doi.org/10.1109/17.293377

Boyer, E.L. (1990). Scholarship Reconsidered, Priorities of the Professoriate. Special Report of The Carnegie Foundation for the Advancement of Teaching, 18-21.

Bruce, C., Pham, B., \& Stoodley, I. (2004). Constituting the significance and value of research: Views from information technology academics and industry professionals. Studies in Higher Education, 29(2), 219-238. http://dx.doi.org/10.1080/0307507042000190804

Burton M.A. (1989). Experiences with the Irrigation Management Game. Irrigation and Drainage Systems, 3(3), 217-228. http://dx.doi.org/10.1007/BF01112806

Câmara, A. (2008). Personal Interview with António Câmara. December.

Carlile, P. (2002). A pragmatic view of knowledge and boundaries: Boundary objects in new product development. Organization Science, 13(4), 442-455.

http://dx.doi.org/10.1287/orsc.13.4.442.2953

Carstensen, A.K., \& Bernhard, J. (2009). Student learning in an electric circuit theory course: Critical aspects and task design. European Journal of Engineering Education, 34(4), 393408. http://dx.doi.org/10.1080/03043790902990315

COTEC (2005). António Câmara Awarded Renowned Portuguese 2006 Prémio Pessoa, COTEC Portugal. Available at:

http://www.cotecportugal.pt/index.php?option=com content\&task=view\&id=140\&Itemid $=319$

Coyle, E.J., Jamieson, L.H., Oakes, W.C. (2006). Integrating Engineering Education and Community Service: Themes for the Future of Engineering Education. Journal of Engineering Education, 95(1), 7-11. http://dx.doi.org/10.1002/j.2168-9830.2006.tb00873.x

Denning, S. (2012). What killed Michael Porter's Monitor Group? The one force that really matters. Forbes, 20 November.

Dias, E. (2007). YDreams Empreendedorismo. Public presentation at Instituto Superior Técnico, Lisbon, 18 April. 
Domal, V. (2010). Comparing Engineering Practice in South Asia and Australia. Thesis PhD. Perth: The University of Western Australia.

Du X., de Graaff E., \& Kolmos A. (Eds) (2009). Research on PBL Practice in Engineering Education. Sense Publishers Rotterdam, Boston, Tapei.

Eisenhardt, K. (1989). Building Theories From Case Study Research, Academy of Management. The Academy of Management Review, 14(4), 532-550.

Eisenhardt, K., \& Graebner, M. (2007). Theory Building from Cases: Opportunities and Challenges. Academy of Management Journal, 50(1), 25-32.

http://dx.doi.org/10.5465/AMJ.2007.24160888

Exame Informática (2010). Instituto Pedro Nunes ganha prémio de melhor incubadora. Available at: http://aeiou.exameinformatica.pt/instituto-pedro-nunes-ganha-premio-de-melhorincubadora-de-tecnologias-do-mundo $=f 1007850$

Faulkner, W. (2007). Nuts and Bolts and People. Social Studies of Science, 37(3), 331-356. http://dx.doi.org/10.1177/0306312706072175

Felder, R.M., \& Brent, R. (2003). Designing and Teaching Courses to Satisfy the ABET Engineering Criteria. Journal of Engineering Education, 92(1), 7-25. http://dx.doi.org/10.1002/j.2168-9830.2003.tb00734.x

Flyvbjerg, B. (2006). Five Misunderstandings About Case-Study Research. Qualitative Inquiry, 12(2), 219-245, Sage Publications. http://dx.doi.org/10.1177/1077800405284363

Haberberg, A. (2000). Swatting SWOT. Strategy. September. Available at: http://www2.wmin.ac.uk/haberba/SwatSWOT.htm

Hamel, G. (2000). Leading the Revolution. New York: Plume, Penguin Books.

Hamel, G., \& Breen, B. (2007). The Future of Management, p. 91. Harvard Business School Press

Harford, T. (2011). Adapt, why success always starts with failure, p. 237. New York: FSG.

Heywood, J. (2014). Personal communication, 1, March 2014

Hill T., \& Westerbrook R. (1997). SWOT analysis: It's time for a product recall. Long Range Planning, 30(1), 46-52. ISSN 0024-6301. http://dx.doi.org/10.1016/S0024-6301(96)00095-7

Jarzabkowski, P., Giulietti, M., \& Oliveira, B. (2009). Building a strategy toolkit - lessons from business. Advanced Institute of Management Executive Briefing. ISBN 978-1-906087-24-1.

Jiang, B., \& Koller, T.M. (2006). Data focus: a long-term look at ROIC. McKinsey Quarterly, 1. 
Jornal de Negocios (2010a). YDreams cria empresa no Cartaxo para cotar nos EUA. Jornal de Negocios, 22 June.

Jornal de Negocios (2010b). YDreams voa para a bolsa de Frankfurt. Jornal de Negocios, 29 November.

Jornal i (2010). Innovação: Os Portuguese são demasiados sofisticados. Jornal i, 19 October.

Korte, R.F., Sheppard, S.D., \& Jordan, W. (2008). A Qualitative Study of the Early Work Experiences of Recent Graduates in Engineering. Paper presented at the American Society for Engineering Education, Pittsburgh. June 22-26.

Kowtha, N.R. (2008). Engineering the Engineers: Socialization Tactics and New Engineer Adjustment in Organizations. IEEE Trans. Eng. Manage., 55(1), February. http://dx.doi.org/10.1109/TEM.2007.912809

Lattuca, L.R., Terenzini, P.T., \& Volkwein, J.F. (2006). Engineering Change: A Study of the Impact of EC 2000. ABET, Inc. Available at: http://www.abet.org/engineering-change/

Leydens, J.A. (2012). Sociotechnical communication in engineering: An exploration and unveiling of common myths. Engineering Studies, 4(1), 1-9.

http://dx.doi.org/10.1080/19378629.2012.662851

Mann, L., Dall'Alba, G., \& Radcliffe, D. (2007). Using phenomenography to investigate different ways of experiencing sustainable design. Proceedings of the ASEE 2007 Annual Conference. ASEE 2007, Hawaii, 25-27 June.

Marton, F. (1989). Towards a pedagogy of content. Educational Psychologist, 24(1), 1-23. http://dx.doi.org/10.1207/s15326985ep2401_1

Mazur, L.M., \& Chen, S-J. (2010). Evaluation of Industrial Engineering Students' Competencies for Process Improvement in Hospitals. Journal of Industrial Engineering and Management, 3(3), 603-628. http://dx.doi.org/10.3926/jiem.2010.v3n3.p603-628

Mintzberg, H. (2009). Managing. Harlow, Pearson.

Nakamura T., Takashima A., \& Mikami A. (2010). The use of agents to represent learners in role-play training. Education Engineering (EDUCON), 2010 IEEE, Madrid, 17 April.

Nakamura, T., Taguchi, E., Hirose D., Masahiro I., Takashima A. (2011). Role-Play Training for Project Management Education Using a Mentor Agent, 3, pp.175-180. IEEE/WIC/ACM International Conferences on Web Intelligence and Intelligent Agent Technology.

National Academy of Engineering (2004). The Engineer of 2020: Visions of Engineering in the New Century. Washington, DC: The National Academy Press. 
Nielsen, K., \& Heymann, M. (2012). Winds of change: communication and wind power technology development in Denmark and Germany from 1973 to ca. 1985. Engineering Studies, 4(1).

Nobre, E. (2009). Personal Interview with Edmundo Nobre. January.

Porter, M. (2008). The Five Competitive Forces That Shape Strategy. Harvard Business Review, 86(1).

Reuters (2010). YDreams - partners with Canesta, Inc. to Develop an Augmented Reality Solution. Available at: http://www.reuters.com/article/2010/05/24/idUS110034+24-May-2010+BW20100524

Sandberg, J. (2000). Understanding human competence at work: an interpretative approach. Academy of Management Journal, 43(1), 9-25. http://dx.doi.org/10.2307/1556383

Savin-Baden, M. (2007). Challenging Models and Perspectives of Problem-Based Learning. In De Graaff, E. \& Kolmos, A. (Eds.). Management of Change: Implementation of ProblemBased and Project-Based Learning in Engineering, pp. 9-30. Rotterdam/Taipei: Sense Publishers.

Sousa, H, (1999). Portugal at the Millennium. Centre for Enterprise and Economic Development Research/Middlesex University, Canning House, London, 21st May. Available at: http://repositorium.sdum.uminho.pt/bitstream/1822/2692/1/helenasousa MilleniumChapter 2002.pdf

Spinks, N., Silburn, N., \& Birchall, D. (2006). Educating Engineers for the 21st Century: the Industry View. Report from the Henley Management College for the Royal Academy of Engineering.

Star, S.L., \& Griesemer, J. R. (1989). Institutional ecology, 'Translations' and boundary objects: Amateurs and professionals in Berkeley's museum of vertebrate zoology. Social Studies of Science, 19(3), 387-420. http://dx.doi.org/10.1177/030631289019003001

Strategos, (2009). Business Innovation Survey Report, Portugal. Available at: http://www.strategos.com/?target=publications

Swarat, S., Light, G., Park, E.-J., \& Drane, D. (2010). A typology of undergraduate students'conceptions of size and scale: Identifying and characterizing conceptual variation. Journal of Research in Science Teaching, 48(5), 512-533. http://dx.doi.org/10.1002/tea.20403

Trevelyan, J. (2010). Reconstructing engineering from practice. Engineering Studies. http://dx.doi.org/10.1080/19378629.2010.520135

Trevelyan, J. (2013). Towards a theoretical framework for engineering practice. In Williams, B., Figueiredo, J. \& Trevelyan J.P. Engineering Practice in a Global Context. Understanding the Technical and Social. London: CRC Press/Taylor and Francis. 
Trevelyan, J.P., \& Tilli, S. (2007). Published Research on Engineering Work. Journal of Professional Issues in Engineering Education and Practice, 133(4), 300-307. http://dx.doi.org/10.1061/(ASCE)1052-3928(2007)133:4(300)

Trompette P., \& Vinck D. (2009). Revisiting the notion of boundary object. Revue d'Anthropologie des Connaissances, 3(1), 3-25. http://dx.doi.org/10.3917/rac.006.0003

Vinck, D. (Ed.) (2003). Everyday Engineering: An Ethnography of Design and Innovation. Boston: MIT Press.

Williams B., \& Figueiredo, J. (2011). Engineering practice - inputs for course design. Proceedings of the IEEE Global Engineering Education Conference, Amman Jordan, 4-6 April, pp. 809-815. Available at: http://ieeexplore.ieee.org/xpl/freeabs all.jsp?arnumber $=5773235$

Williams, B., \& Figueiredo, J. (2013). Finding workable solutions: Portuguese engineering experience. In Engineering Practice in a Global Context: Understanding the Technical and the Social. Bill Williams, José Figueiredo \& James Trevelyan (Eds.). CRCPress/Taylor \& Francis. http://dx.doi.org/10.1201/b15792-8

Wired UK (2011). Sigas: Santander's friendly bank bots. August.

Article's contents are provided on a Attribution-Non Commercial 3.0 Creative commons license. Readers are allowed to copy, distribute and communicate article's contents, provided the author's and Journal of Industrial Engineering and Management's names are included. 